\title{
COMPUTATIONAL AND PHARMACOLOGICAL EVALUATION OF HETEROCYCLIC 1,3,4-OXADIAZOLE AND PYRAZOLES NOVEL DERIVATIVES FOR TOXICITY ASSESSMENT, TUMOUR INHIBITION, ANTIOXIDANT, ANALGESIC AND ANTI-INFLAMMATORY ACTIONS
}

\author{
MUHAMMAD FAHEEM $^{1}$, ARIF-ULLAH KHAN ${ }^{1 *}$, HUMAIRA NADEEM $^{2}$, FAWAD ALI $^{1,3}$ \\ ${ }^{I}$ Department of Pharmacology, Riphah Institute of Pharmaceutical Sciences, Riphah International University, Islamabad, Pakistan \\ ${ }^{2}$ Department of Pharmaceutical Chemistry, Riphah Institute of Pharmaceutical Sciences, Riphah International University, \\ Islamabad, Pakistan \\ ${ }^{3}$ Department of Pharmacy, Kohat University of Science and Technology, Kohat, Pakistan
}

*corresponding author: arif.ullah@riphah.edu.pk

\begin{abstract}
The present research work was focused on the computational and pharmacological potential of 1,3,4-oxadiazole and pyrazole novel derivatives including: $N$-\{4-[(5-sulfanyl-1,3,4-oxadiazol-2-yl)methoxy]phenyl acetamide (a3), 5-[(naphthalen-2-yloxy) methyl]- 1,3,4-oxadiazole-2-thiol (b3), 3-phenyl-5-(o-hydroxyphenyl)-1-[2-(p-N-acetylaminophenoxyacetylpyrazole (a6) and 3phenyl-5-(o-hydroxy phenyl)-1-[2-(2'-naphthyloxy)acetyl] pyrazole (b6). Docking against targets including epidermal growth factor receptor (EGFR), tubulin, cyclooxygenase-2 (COX-2) and 5-lypoxygenase (5-LOX) were followed by the investigation of a3, b3, a6, and b6 for toxicity, tumour inhibition, free radical scavenging, analgesic and anti-inflammatory potential. Compound a3 showed binding and moderate inhibitory effects in all assays, b3 possess good affinity for COX-2 and 5-LOX which can be correlated to its highest analgesic and anti-inflammatory effects. Compound a6 showed binding to all targets and antioxidant potential, with an $\mathrm{EC}_{50}$ value of $100 \mu \mathrm{g} / \mathrm{mL}$, b6 formed two hydrogen bonds with tubulin and was the most potent in the toxicity assessment and tumour inhibition with $\mathrm{LC}_{50}$ values of 2.47 and $5.51 \mu \mathrm{g} / \mathrm{mL}$ respectively.
\end{abstract}

\section{Rezumat}

Cercetările prezentate au fost axate pe potențialul computațional și farmacologic al derivaților noi ai 1,3,4-oxadiazolului şi pirazolului incluzând: N-\{4-[(5-sulfanil-1,3,4-oxadiazol-2- (a3), 5-[(naftalen-2-iloxi) metil]-1,3,4-oxadiazol-2tiol (b3), 3fenil-5-(pN-acetilaminofenoxiacetilpirazol (a6) și 3-fenil-5-(o-hidroxifenil)-1-[2-(2'-naftiloxi)acetil]pirazol (b6). Am realizat studii de andocare pentru receptorul factorului de creștere epidermic, tubulină, ciclooxigenaza-2 (COX-2) şi 5lipoxigenaza (5-LOX), urmate de evaluarea toxicității, precum și a potenţialului antitumoral, antioxidant, antiinflamator şi analgezic al acestora.

Keywords: oxadiazole, pyrazoles, docking, antioxidant, analgesic, anti-inflammatory

\section{Introduction}

We investigated computational and pharmacological potential of 1,3,4 oxadiazoles and pyrazole novel derivatives. These are five membered, heterocyclic and bioactive compounds with diverse biological actions. The important pharmacological potentials of 1,3,4-oxadiazole are analgesic [1], anti-inflammatory [2], antibacterial [3] and anticancer activities. The currently available anticancer drug (raltegravir) possess the oxadiazole nucleus [4].

Pyrazoles derivatives also show some pharmacological actions like anticancer [5], antioxidant [6], analgesic and anti-inflammatory activities $[7,8]$. The selection of these newly synthesized derivatives is because of their broad pharmacological spectrum with hope to results in development of new active drugs which can be used in different diseases at a time. Hence this research work is focused to study some 1,3,4oxadiazole and pyrazole derivatives which are $N$ \{4-[(5-sulfanyl-1,3,4-oxadiazol-2-yl)methoxy]phenyl acetamide (a3), 5-[(naphthalen-2-yloxy)methyl]-1,3,4oxadiazole-2-thiol (b3), 3-phenyl-5-(o-hydroxyphenyl)-1-[2-(p-N-acetylamino-phenoxyacetylpyrazole (a6) and 3-phenyl-5-(o-hydroxy phenyl)1-[2-(2'-naphthyloxy)acetyl] pyrazole (b6), as shown in (Figure 1) 
<smiles>CC(=O)Nc1ccc(OCc2nnc(S)o2)cc1</smiles>

a3<smiles>CC(=O)Nc1ccc(OCC(=O)n2nc(-c3ccccc3)cc2-c2ccccc2O)cc1</smiles>

a6<smiles>Sc1nnc(COc2ccc3ccccc3c2)o1</smiles>

b3<smiles>O=C(COc1ccc2ccccc2c1)n1nc(-c2ccccc2)cc1-c1ccccc1O</smiles>

b6

Figure 1.

Chemical structures of compounds: $N$ - $\{4-[(5-$ sulfanyl-1,3,4-oxadiazol-2yl)methoxy] phenyl $\}$ acetamide (a3), 5[(naphthalen-2-yloxy)methyl]-1,3,4-oxadiaszole2-thiol (b3), 3-phenyl5-(o-hydroxyphenyl)-1-[2-(p-N-acetylaminophenoxy)acetylpyrazole (a6) and 3phenyl-5-(o-hydroxyphenyl)-1-[2-(2'-naphthyloxy)acetyl]pyrazole (b6).

The compounds a3 and a6 were synthesized using 2-[4-(Acetylamino) phenoxy] acetic acid hydrazide as starting material, while b3 and b6 were synthesized from 2-(Naphthalene-2'-yloxy) acetic acid hydrazide. The oxadiazole derivatives ( $\mathrm{a} 3$ and $\mathrm{b} 3$ ) were prepared by the condensation of the respective hydrazides with carbon disulfide in the presence of potassium hydroxide, following standard procedure [9, 10]. For the synthesis of the pyrazole derivatives ( $\mathrm{a} 6$ and b6), the corresponding hydrazides were condensed with appropriate chalcones in the presence of acetic acid and hydrochloric acid [11]. All the synthesized compounds were characterized by spectroscopic data. These derivatives were first docked against different targets namely epidermal growth factor receptor (EGFR), tubulin, cyclooxygenase-2 (COX-2) and 5lypoxygenase (5-LOX) to in order to establish their binding affinities through computational techniques. The purpose of the selection of biological targets including EGFR, tubulin, COX-2, 5-LOX is to confirm the binding of mentioned derivatives with these targets to get an idea about their anticancer, analgesic and anti-inflammatory actions and then to process these compounds for various in vitro and in-vivo activities, i.e. cytotoxicity, antitumor, antioxidant, anti-nociceptive and anti-inflammatory activities.

\section{Materials and Methods}

Materials. Acetic acid, agar, ascorbic acid, carrageenan, diclofenac sodium, dimethyl sulphoxide (DMSO), diphenyle picryle hydrazine (DPPH), methanol, potassium iodide (KI), methotrexate and vincristine (Sigma Chemicals., Dt. Louis, MO, USA) and high hatching rate Artemia salina or Brine shrimp eggs (Xiamen Mincheng Imp \& Exp Co., Ltd, Fujian, China).
Experimental animals. Balb-C mice (25 - $30 \mathrm{~g})$ were utilized for the in-vivo studies of the test compounds. The experiments were performed according to the rules of Institute of Laboratory Animal Resource, Commission on Life Sciences University, National Research Council [12] and approved by the Ethical Committee of Riphah Institute Pharmaceutical Sciences, Riphah International University (Ref No. REC/RIPS/ 2016/002).

Computational evaluation. Ligand were drawn in 3D format and saved as PDB file by Discovery studio client 2016. The standards, erlotinib (PubChem CID: 176870), vincristine (PubChem CID: 249332), diclofenac sodium (PubChem CID: 5018304) and zileuton (PubChem CID: 60490) retrieved in $\mathrm{xml}$ format from PubChem data base (www.pubchem. ncbi.nlm.nih.gov) were converted to PDB format by Open Babel JUI. Four targets obtained from protein data bank (www.rcsb.org) with their respective PDB entries were EGFR (PDB entry: 5JEB), Tubulin (PDB entry: 5JCO), COX-2 (PDB entry: 5IKQ) and 5-LOX (PDB entry: 3V92). Docking and post docking analysis was carried out through Patch dock and Discovery studio client 2016 respectively [13].

Toxicity assessment. Determination was carried out by brine shrimp lethality assay [14]. After hatching of brine shrimp eggs, the larvae (nauplii) were subjected to serial dilution of the each of the test compound in 5\% DMSO. The number of larvae killed was counted after 24 hours of incubation and $\mathrm{LC}_{50}$ values were then calculated.

Tumour inhibition study. Fresh potatoes after sterilization were placed in $1.5 \%$ sterilized agar plates. The yeast extract media was autoclaved, inoculated with Agrobacterium tumefacien (ATCC0120), incubated for 48 hours at $28^{\circ} \mathrm{C}$ and standardized to $1 \times 10^{9}$ colony forming unit (CFU). Mixture of $50 \mu \mathrm{L}$ of media of 
bacterial solution and $50 \mu \mathrm{L}$ of each serially prepared test compound in 5\% DMSO was applied on previously made plates of potatoes disc and incubated for $14-21$ days. Application of the Lugol's reagent (5\% iodine and $10 \% \mathrm{KI}$ ) results in staining of the discs. The tumours were counted based on colour difference under microscope [15].

Antioxidant analysis. DPPH free radical scavenging assay was used to determine antioxidant activity [16]. $3 \mathrm{~mL}$ of $1 \mathrm{mM}$ DPPH in methanol was added to both serially made test compounds in 5\% DMSO and control ( $5 \%$ DMSO). The solution was allowed to stand for $30 \mathrm{~min}$ and absorbance was checked at $517 \mathrm{~nm}$, using UV spectrophotometer. Ascorbic acid was served as positive control.

Antinociceptive activity. The analgesic potential of the test compounds was determined by acetic acidinduced writhing in mice [17]. Five groups with each group comprised of 5 animals after 12 hours fasting were administered with i.p. injection of saline solution $(10 \mathrm{~mL} / \mathrm{kg})$, test compounds $(10,20$ and $30 \mathrm{mg} / \mathrm{kg})$ and diclofenac sodium $(20 \mathrm{mg} / \mathrm{kg}) 30 \mathrm{~min}$ prior to the i.p. injection of $0.1 \mathrm{~mL} / \mathrm{kg}$ of $0.7 \% \mathrm{v} / \mathrm{v}$ acetic acid to induce pain. The pain perception was recorded as a stretch of hind limb and abdominal constriction called as writhe after 5 minutes of acetic acid administration for a period of $20 \mathrm{~min}$.

Anti-inflammatory potential. The anti-inflammatory potential of all the four compounds was determined by using carrageenan induced paw oedema [18]. Four groups with each group comprised of 5 animals after 12 hours fasting were administered with the i.p. injection of saline solution $(10 \mathrm{~mL} / \mathrm{kg})$, test compounds and diclofenac sodium $30 \mathrm{~min}$ prior to $0.1 \mathrm{~mL} / \mathrm{kg}$ of $1 \%$ carrageenan (subplantar injection) in distilled water for induction of acute paw oedema. The changes in paw volume were recorded by using plethysmometer (model: UGO Basile S.R.L, 7141) after 0, 1, 2, 3 and 4 hours of carrageenan injection.

Acute toxicity assay. Mice were divided into four groups with each containing five animals. Group I was assigned as saline group $(10 \mathrm{~mL} / \mathrm{kg})$. Group II, III and IV were utilised to administer each test compound at doses of 250,500 and $750 \mathrm{mg} / \mathrm{kg}$ through the i.p. route and the animals were checked for toxicity and mortality [19].

Statistical analysis. Data are expressed as Mean \pm standard error of mean (SEM). The results analysed using one-way analysis of variance (ANOVA), with Tukey post-hoc test. $\mathrm{p}<0.05$ was noted, as significantly different. The bar-graph was analysed using the Graph Pad program (Graph-Pad, San-Diego-CA, USA).

\section{Results and Discussion}

In-silico study

Before exploring pharmacological activities, test compounds were subjected to docking studies against four different targets involved in cancer, pain and inflammation. To predict the anticancer potential, a3, b3, a6 and b6 were docked against two targets, which were EGFR and tubulin. Docking against EGFR showed that a3 formed single conventional hydrogen bond at Asn 972 residue with binding energy level of $-218.99 \mathrm{Kcal} / \mathrm{mol}$. b3 formed conventional hydrogen bond through Asp 831 residue with binding energy level of $-297.65 \mathrm{Kcal} / \mathrm{mol}$. a6 with binding energy level of $-182.51 \mathrm{Kcal} / \mathrm{mol}$ showed conventional hydrogen bond at Arg 817 residue. b6 with binding energy level of $-224.22 \mathrm{Kcal} / \mathrm{mol}$ formed conventional hydrogen bond at Tyr 845 residue. Erlotinib with binding energy level of $279.43 \mathrm{Kcal} / \mathrm{mol}$ showed single hydrogen bonds at Thr 830 residue. The result shows that almost all the test compounds and the reference drug show similar binding by forming single conventional hydrogen bond. The hydrogen bonding of a3, b3, a6, b6 and erlotinib with EGFR is shown in Figure 2.

The results of E-values, hydrogen bonds and amino acid residues of a3, b3, a6, b6 and erlotinib against EGFR are presented in Table I. Tubulin was utilized as second target for anticancer activity. a3 at binding energy level of $-209.82 \mathrm{Kcal} / \mathrm{mol}$ showed two hydrogen bonds at Asn 329 and Val 170 residues. b3 at binding energy level of $-207.07 \mathrm{Kcal} / \mathrm{mol}$ formed single hydrogen bond with Tyr 224 residue.

Table I

Composition and codification of metronidazole gel formulations

\begin{tabular}{|c|c|c|c|}
\hline Test sample & E-value (Kcal/mol) & Hydrogen bond & Amino acid residue \\
\hline a3 & -218.99 & 1 & Asparagine \\
\hline b3 & -297.65 & 1 & Aspartate \\
\hline a6 & -182.51 & 1 & Arginine \\
\hline b6 & -224.22 & 1 & Tyrosine \\
\hline Erlotinib & -279.43 & 1 & Threonine \\
\hline
\end{tabular}




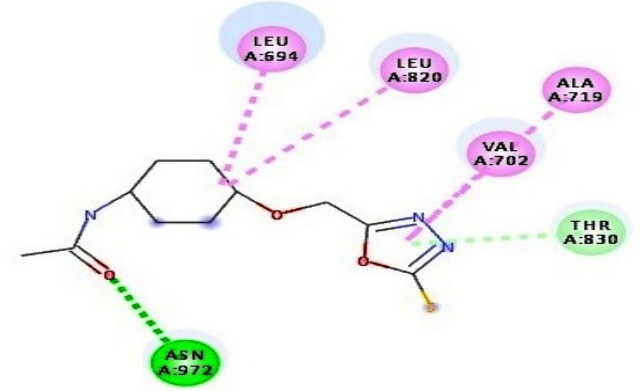

A

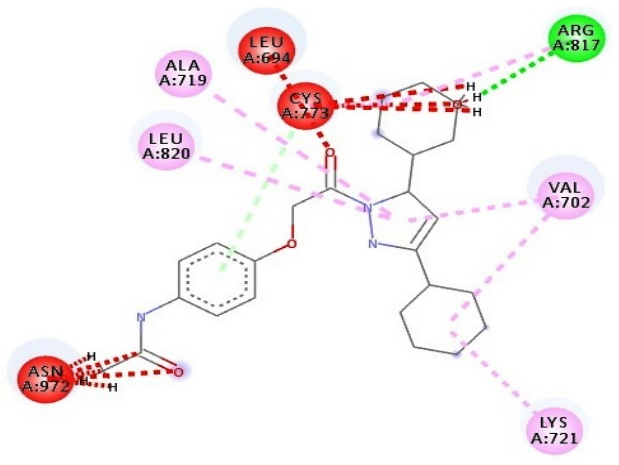

C

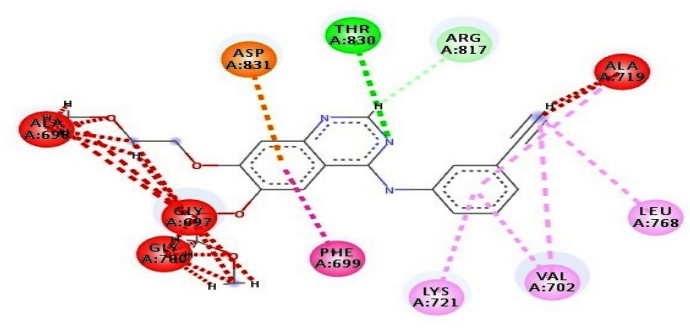

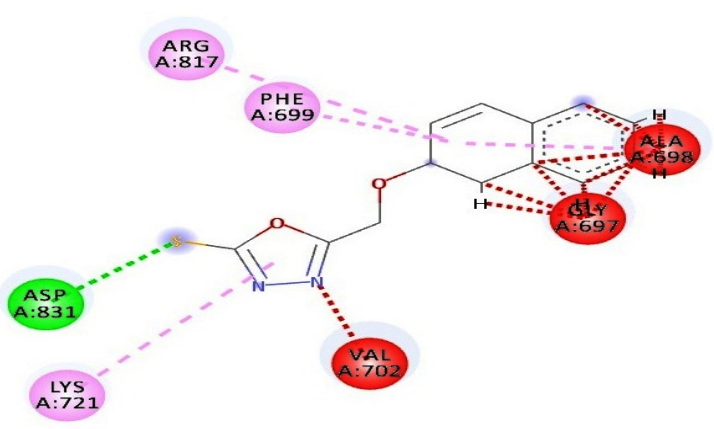

B

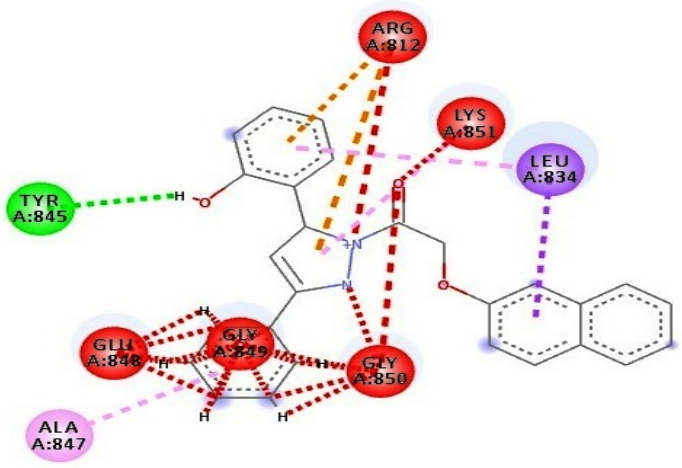

D

Interactions

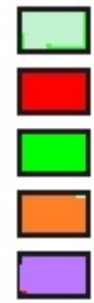

Van der wall forces

Unfavourable bumps

Conventional Hydrofen bond

Attractive Charges

Covalant Bond

E

Figure 2.

A, B, C, D and $\mathbf{E}$ represents hydrogen bonds with amino acid residues after docking of $N-\{4-[(5$ sulfanyl- $1,3,4$ oxadiazol-2-yl)methoxy]phenyl acetamide (a3), 5-[(naphthalen-2yloxy)methyl] 1,3,4oxadiazole-2 thiol (b3), 3phenyl-5-(o-hydroxyphenyl)-1-[2-(p-Nacetylaminophenoxy) acetyl] pyrazole (a6), 3-phenyl-5-(o-hydroxyphenyl)-1-[2 (2'naphthyloxy)acetyl] pyrazole (b6) and erlotinib respectively with target epidermal growth factor receptor (EGFR), drawn through Biovia Discovery Studio Visualizer client 2016.

a6 showed one conventional hydrogen bond at Ser 138 residue with binding energy level of -168.13 $\mathrm{Kcal} / \mathrm{mol}$. b6 formed two hydrogen bonds at Arg 282 and Asp 295 residues. Vincristine with binding energy level of $-235.27 \mathrm{Kcal} / \mathrm{mol}$ showed three hydrogen bonds at Gly 402, His 396 and Leu 395 residues. Figure 3 shows hydrogen bonding of a3, b3, a6, b6 and vincristine with tubulin.

The results of E-values, hydrogen bonds and amino acid residues of $a 3, b 3, a 6, b 6$ and vincristine against tubulin are shown in Table II. In case of docking against $\mathrm{COX}-2$, a3 showed single conventional hydrogen bond at Tyr 385 residue with binding energy level of $-209.65 \mathrm{Kcal} / \mathrm{mol}$. b3 with binding energy level of $218.69 \mathrm{Kcal} / \mathrm{mol}$ formed two conventional hydrogen bonds with Ala 554 Arg 44 residues. a6 with binding energy level of $153.60 \mathrm{Kcal} / \mathrm{mol}$ showed hydrogen bonds at Gly 45, Lys 138 and Lys 546 residues. 


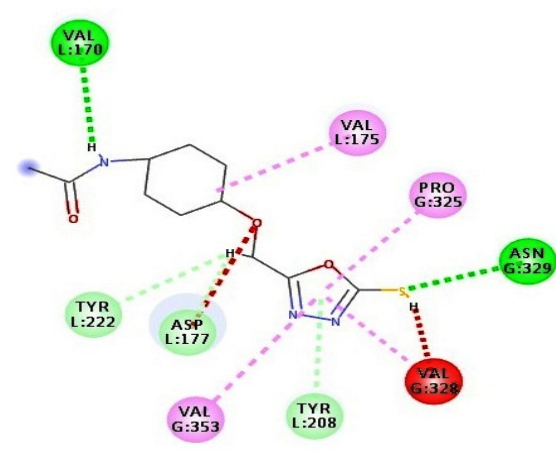

A

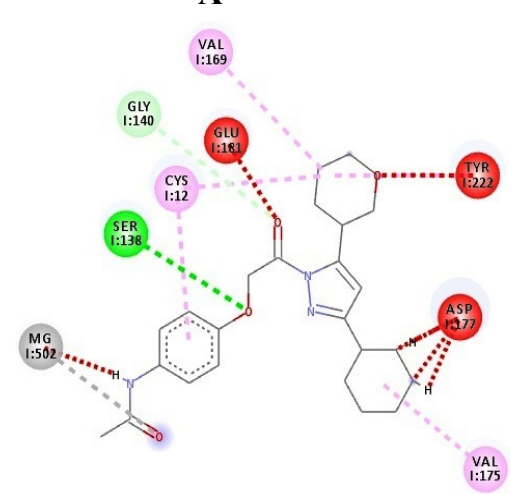

C

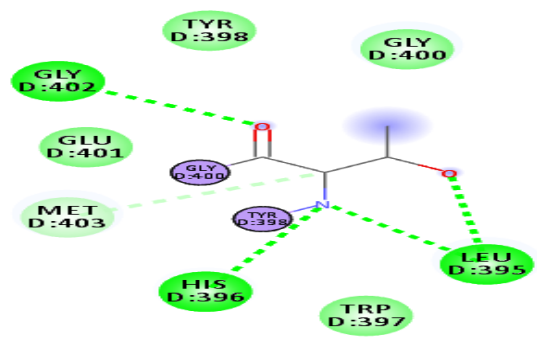

$\mathrm{E}$

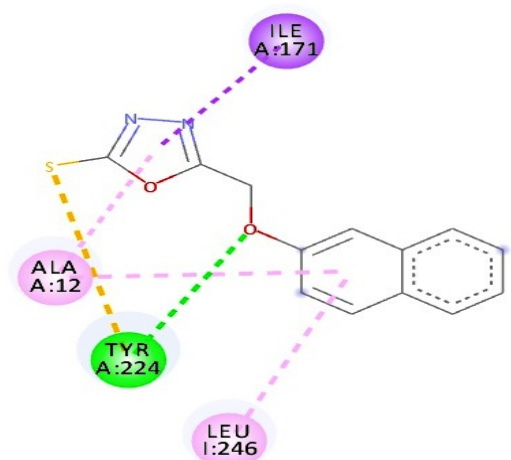

B

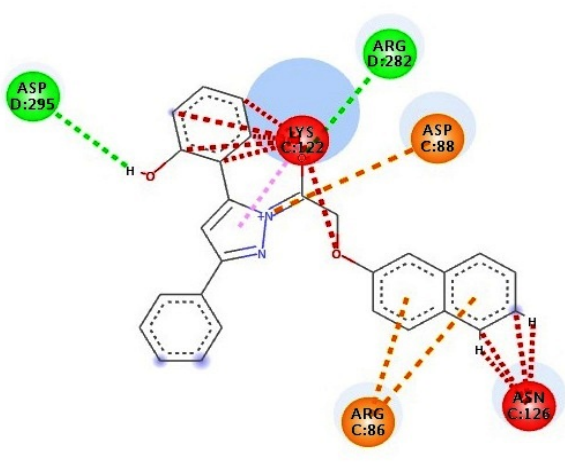

D

Interactions

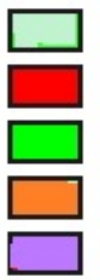

Van der wall forces

Unfavourable bumps

Conventional Hydrofen bond

Attractive Charges

Covalant Bond

Figure 3.

$\mathbf{A}, \mathbf{B}, \mathbf{C}, \mathbf{D}$ and $\mathbf{E}$ represent hydrogen bonds with amino acid residues after docking of $N-\{4-[(5$ sulfanyl-1,3,4 oxadiazol-2-yl)methoxy]phenyl acetamide (a3), 5-[(naphthalen-2yloxy)methyl] 1,3,4oxadiazole-2thiol (b3), 3phenyl-5-(o-hydroxyphenyl)-1-[2-(p-Nacetylaminophenoxy) acetyl] pyrazole (a6) and 3-phenyl-5-(o-hydroxyphenyl)-1-[2(2'naphthyloxy)acetyl] pyrazole (b6) and vincristine respectively with target tubulin, drawn through

Biovia Discovery Studio Visualizer client 2016.

Table II

E-values, hydrogen bonds and amino acid residues shown after docking of $N$ - $\{4$-[(5-sulfanyl-1,3,4-oxadiazol-2-yl)methoxy] phenylacetamide (a3), 5-[(naphthalen-2-yloxy)methyl]-1,3,4-oxadiazole-2-thiol (b3) 3-phenyl-5-(ohydroxyphenyl)-1-[2-(p-N-acetylaminphenoxy) acetyl] pyrazole (a6) 3-phenyl-5-(o-hydroxyphenyl)-1-[2-(2'naphthyloxy)acetyl] pyrazole (b6) and vincristine against tubulin, interpreted through Biovia Discovery Studio

\begin{tabular}{|c|c|c|c|}
\hline Test sample & E-value (Kcal/mol) & Hydrogen bond & Amino acid residue \\
\hline a3 & -209.82 & 2 & Asparagine, valine \\
\hline b3 & -207.07 & 2 & Tyrosine \\
\hline a6 & -168.13 & 1 & Serine \\
\hline b6 & -163.79 & 2 & Arginine, aspartate \\
\hline Vincristine & -235.27 & 3 & Glycine, histadine, leucine \\
\hline
\end{tabular}

Single hydrogen bond $228.85 \mathrm{Kcal} / \mathrm{mol}$ was identified for b6. Diclofenac sodium with binding energy level of $238.65 \mathrm{Kcal} / \mathrm{mol}$ formed three hydrogen bonds at
Gly 225, His 226 and Val 228. The hydrogen bonding of a3, b3, a6, b6 and diclofenac sodium with COX-2 is shown in Figure 4. 
FARMACIA, 2018, Vol. 66, 5

Table III presents results of E-values, hydrogen bonds and amino acid residues of a3, b3, a6, b6 and diclofenac sodium against COX-2. Zileuton was utilized as forth target. a3 with binding energy level of $-239.56 \mathrm{Kcal} / \mathrm{mol}$ showed single conventional hydrogen bond at Gly 363 residue. b3 with binding

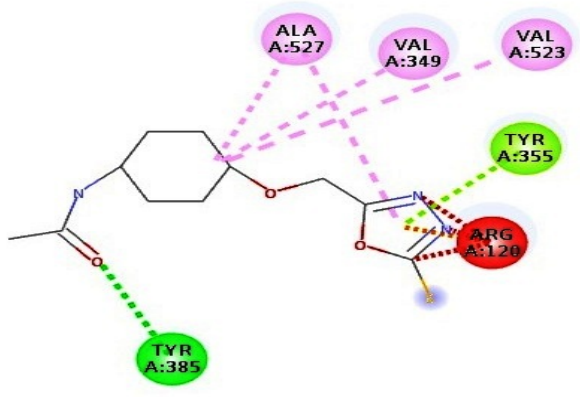

A

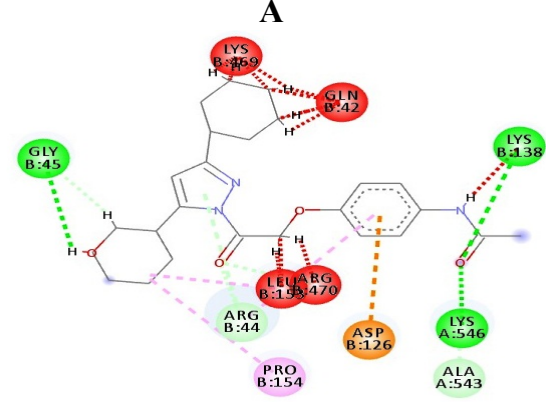

C

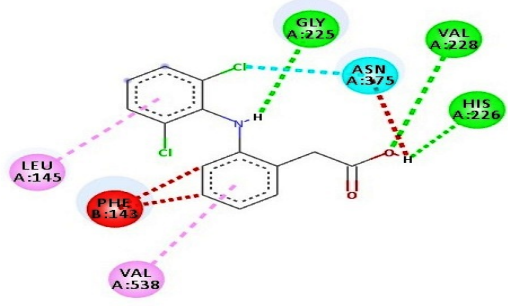

E energy level of $-204.65 \mathrm{Kcal} / \mathrm{mol}$ formed two hydrogen bonds at Arg 101 and Arg 138. a6 with binding energy level of $-111.78 \mathrm{Kcal} / \mathrm{mol}$ formed single hydrogen bond at Thr 366. b6 with binding energy level of $215.45 \mathrm{Kcal} / \mathrm{mol}$ showed single hydrogen bond at Arg 68.

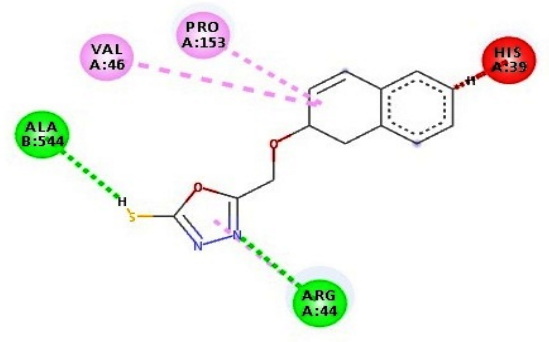

B

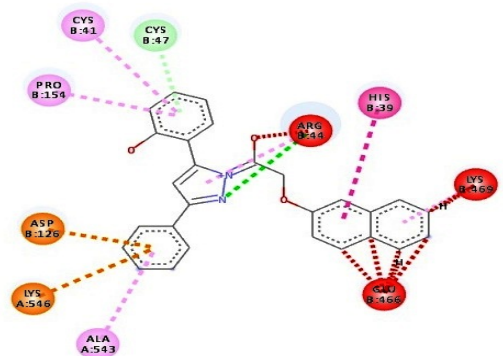

D

\section{Interactions}

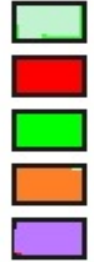

Van der wall forces

Unfavourable bumps

Conventional Hydrofen bond

Attractive Charges

Covalant Bond

Figure 4.

$\mathbf{A}, \mathbf{B}, \mathbf{C}, \mathbf{D}$ and $\mathbf{E}$ represent hydrogen bonds with amino acid residues after docking of $N-\{4-[(5$ sulfanyl-1,3,4 oxadiazol-2-yl)methoxy]phenyl acetamide (a3), 5-[(naphthalen-2yloxy)methyl] 1,3,4oxadiazole-2thiol (b3), 3phenyl-5-(o-hydroxyphenyl)-1-[2-(p-Nacetylaminophenoxy) acetyl] pyrazole (a6) and 3-phenyl-5-(o-hydroxyphenyl)-1-[2 (2'naphthyloxy)acetyl] pyrazole (b6) and diclofenac sodium respectively with target cyclooxygenase-2 (COX-2), drawn through Biovia Discovery Studio Visualizer client 2016

Table III

E-values, hydrogen bonds and amino acid residues shown after docking of $N$ - $\{4-[(5$-sulfanyl-1,3,4-oxadiazol-2-yl)methoxy] phenylacetamide (a3), 5-[(naphthalen-2-yloxy)methyl]-1,3,4-oxadiazole-2-thiol (b3) 3-phenyl-5-(Ohydroxyphenyl)-1-[2-(p-N-acetylaminphenoxy) acetyl] pyrazole (a6) 3-phenyl-5-(O-hydroxyphenyl)-1-[2-(2'naphthyloxy)acetyl] pyrazole (b6) and diclofenac sodium against cycloocygnase-2 (COX-2), interpreted through

Biovia Discovery Studio Visualizer client 2016

\begin{tabular}{|c|c|c|c|}
\hline Test sample & E-value (Kcal/mol) & Hydrogen bond & Amino acid residue \\
\hline a3 & -209.65 & 1 & Tyrosine \\
\hline b3 & -218.69 & 2 & Alanine, arginine \\
\hline a6 & -153.60 & 3 & Glycine, lysine, lysine \\
\hline b6 & -228.85 & 1 & NA \\
\hline Diclofenac sodium & -238.56 & 3 & Glycine, valine, histadine \\
\hline
\end{tabular}


FARMACIA, 2018, Vol. 66, 5

Zileuton with binding energy level of -200.39 $\mathrm{Kcal} / \mathrm{mol}$ formed two hydrogen bonds at Gly 430 and Gly 437. The hydrogen bonding of a3, b3, a6, b6 and zileuton with 5-LOX is shown in Figure 5.

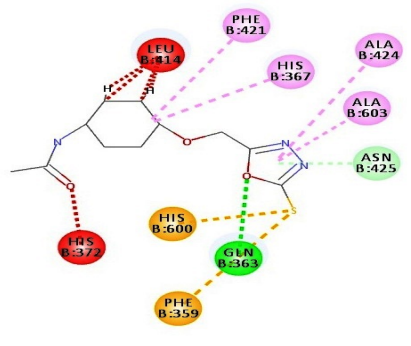

A

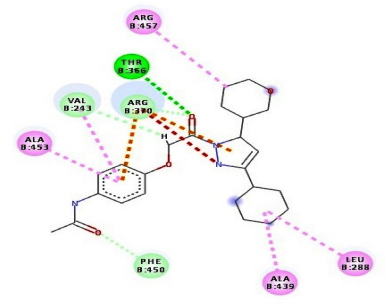

C

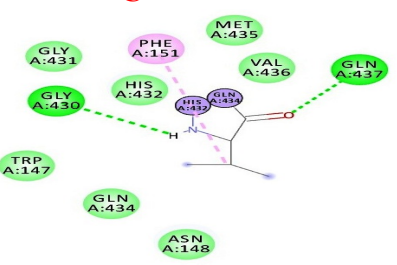

The results of E-values, hydrogen bonds and amino acid residues of a3, b3, a6, b6 and zileuton against 5 -LOX are presented in Table IV.

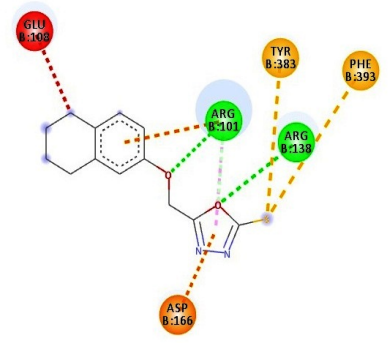

B

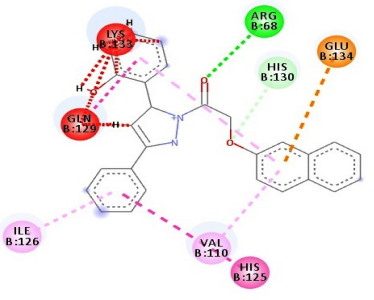

D

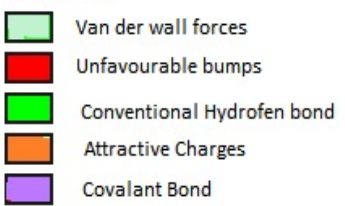

Figure 5.

A, B, C, D and E represent hydrogen bonds with amino acid residues after docking of N-\{4-[(5sulfanyl-1,3,4 oxadiazol-2-yl)methoxy]phenyl acetamide (a3), 5-[(naphthalen-2yloxy)methyl] 1,3,4oxadiazole-2thiol (b3), 3phenyl-5-(o-hydroxyphenyl)-1-[2-(p-Nacetylaminophenoxy)acetyl]pyrazole (a6) and 3-phenyl-5-(ohydroxyphenyl)-1-[2 (2'naphthyloxy)acetyl] pyrazole (b6) and zileuton respectively with target 5-lypooxygenase (5-LOX), drawn through Biovia Discovery Studio Visualizer client 2016

Table IV

E-values, hydrogen bonds and amino acid residues shown after docking of $N$ - $\{4$-[(5-sulfanyl-1,3,4-oxadiazol-2-yl)methoxy] phenylacetamide (a3), 5-[(naphthalen-2-yloxy)methyl]-1,3,4-oxadiazole-2-thiol (b3) 3-phenyl-5-(ohydroxyphenyl)-1-[2-(p-N-acetylaminophenoxy) acetyl] pyrazole (a6) 3-phenyl-5-(o-hydroxyphenyl)-1-[2-(2'naphthyloxy)acetyl] pyrazole (b6) and zileuton against 5-lypooxygenase (5-LOX), interpreted through Biovia

Discovery Studio Visualizer client 2016

\begin{tabular}{|c|c|c|c|}
\hline Test sample & E-value (Kcal/mol) & Hydrogen bonds & Amino acid residue \\
\hline a3 & -239.56 & 1 & Glycine \\
\hline b3 & -204.65 & 2 & Arginine, arginine \\
\hline a6 & -111.78 & 1 & Threonine \\
\hline b6 & -215.45 & 1 & Arginine \\
\hline Zileuton & -200.39 & 2 & Glycine \\
\hline
\end{tabular}

Effect on brine shrimp lethality

The results of concentration-dependant toxicity assessment of a3, b3, a6, b6 and methotrexate at concentration of $1,3,5,10,100,300$ and $1000 \mathrm{ug} / \mathrm{mL}$ are shown in Table $\mathrm{V}$. The larvae remain unaffected in control group (5\% DMSO). The $\mathrm{LC}_{50}$ values recorded for a3, b3, a6, b6 and methotrexate was 5.0, 10.0, $5.75,2.47$ and $3.39 \mu \mathrm{g} / \mathrm{mL}$ respectively. 
Concentration-dependent $(\mu \mathrm{g} / \mathrm{mL})$ toxicity assessment of $N$ - $\{4-[(5-$ sulfanyl-1,3,4-oxadiazol-2-yl) methoxy]phenyl\} acetamide (a3), 5-[(naphthalen-2-yloxy)methyl]-1,3,4-oxadiazole-2-thiol (b3), 3-phenyl-5-(ohydroxyphenyl)-1-[2-(p-N-acetylaminophenoxy) acetyl] pyrazole (a6) 3-phenyl-5-(o-hydroxyphenyl)-1-[2-(2'naphthyloxy)acetyl] pyrazole (b6) and methotrexate against brine shrimps

\begin{tabular}{|c|c|c|c|c|c|c|c|c|}
\hline $\begin{array}{c}\text { Test } \\
\text { sample }\end{array}$ & $\mathbf{1}$ & $\mathbf{3}$ & $\mathbf{5}$ & $\mathbf{1 0}$ & $\mathbf{1 0 0}$ & $\mathbf{3 0 0}$ & $\mathbf{1 0 0 0}$ & $\begin{array}{c}\text { LC } \\
\mathbf{5 0} \\
\text { values }\end{array}$ \\
\hline $\mathrm{a} 3$ & $43.3 \pm 0.33$ & $46.6 \pm 0.33$ & $50.0 \pm 0.0$ & $76.6 \pm 0.33$ & $83.3 \pm 0.33$ & $93.3 \pm 0.33$ & $100.0 \pm 0.0$ & 5.00 \\
\hline $\mathrm{b} 3$ & $33.3 \pm 0.33$ & $36.6 \pm 0.33$ & $43.3 \pm 0.33$ & $50.0 \pm 0.01$ & $53.3 \pm 0.33$ & $56.6 \pm 0.33$ & $60.0 \pm 0.01$ & 10.00 \\
\hline $\mathrm{a} 6$ & $33.3 \pm 0.33$ & $40.0 \pm 0.01$ & $46.6 \pm 0.33$ & $56.6 \pm 0.33$ & $66.6 \pm 0.33$ & $73.3 \pm 0.33$ & $80.0 \pm 0.01$ & 5.75 \\
\hline $\mathrm{b} 6$ & $36.6 \pm 0.33$ & $53.3 \pm 0.33$ & $66.6 \pm 0.33$ & $76.6 \pm 0.33$ & $83.3 \pm 0.33$ & $86.6 \pm 0.33$ & $93.3 \pm 0.33$ & 2.47 \\
\hline MTX & $15.4 \pm 5.1$ & $48.3 \pm 4.5$ & $59.7 \pm 3.5$ & $81.3 \pm 3.50$ & $91.7 \pm 6.7$ & $100 \pm 0.0$ & $100 \pm 0.0$ & 3.39 \\
\hline
\end{tabular}

Values shown are \% age \pm SEM, $n=4$, MTX $=$ methotrexate.

Table VI

Concentration-dependent $(\mu \mathrm{g} / \mathrm{mL})$ antitumor effect $N$ - $\{4-[(5$-sulfanyl-1,3,4-oxadiazol-2-yl) methoxy]phenyl $\}$ acetamide (a3), 5-[(naphthalen-2-yloxy)methyl]-1,3,4-oxadiazole-2-thiol (b3), 3-phenyl-5-(o-hydroxyphenyl)-1-

[2-(p-N-acetylaminophenoxy) acetyl] pyrazole (a6) and 3-phenyl-5-(o-hydroxyphenyl)-1-[2-(2'naphthyloxy)acetyl] pyrazole (b6) and vincristine against tumor inhibition

\begin{tabular}{|c|c|c|c|c|c|c|c|c|}
\hline $\begin{array}{c}\text { Test } \\
\text { sample }\end{array}$ & $\mathbf{1}$ & $\mathbf{3}$ & $\mathbf{5}$ & $\mathbf{1 0}$ & $\mathbf{1 0 0}$ & $\mathbf{3 0 0}$ & $\mathbf{1 0 0 0}$ & $\begin{array}{c}\mathbf{L C}_{\text {50 }} \\
\text { values }\end{array}$ \\
\hline $\mathrm{a} 3$ & $27.7 \pm 0.33$ & $33.4 \pm 0.33$ & $44.9 \pm 0.66$ & $58.0 \pm 0.33$ & $69.5 \pm 0.57$ & $71.0 \pm 0.33$ & $83.0 \pm 0.33$ & 6.65 \\
\hline $\mathrm{b} 3$ & $14.5 \pm 0.33$ & $21.7 \pm 0.57$ & $27.5 \pm 082$ & $33.3 \pm 0.33$ & $40.6 \pm 0.33$ & $53.6 \pm 0.57$ & $69.5 \pm 0.57$ & 190.0 \\
\hline $\mathrm{a} 6$ & $20.3 \pm 0.66$ & $26.0 \pm 0.57$ & $36.2 \pm 0.33$ & $47.8 \pm 0.57$ & $60.8 \pm 0.57$ & $73.9 \pm 0.57$ & $81.1 \pm 0.33$ & 11.83 \\
\hline $\mathrm{b} 6$ & $23.2 \pm 0.33$ & $39.1 \pm 0.57$ & $47.8 \pm 0.57$ & $62.3 \pm 0.33$ & $73.9 \pm 0.00$ & $76.8 \pm 0.33$ & $84.0 \pm 0.33$ & 5.51 \\
\hline
\end{tabular}

Vincristine $=91.3 \pm 1.3 \%$ tumor inhibition at $250 \mu \mathrm{g} / \mathrm{mL}$. Values shown are \%age $\pm \mathrm{SEM}, \mathrm{n}=4$

\section{Effect on tumour inhibition}

The results of concentration-dependant tumour inhibition of a3, b3, a6 and b6 are shown in Table VI. The $\mathrm{LC}_{50}$ values recorded for $\mathrm{a} 3, \mathrm{~b} 3, \mathrm{a} 6$, and $\mathrm{b} 6$ was $6.65,190.0,11.83$ and $5.51 \mu \mathrm{g} / \mathrm{mL}$.

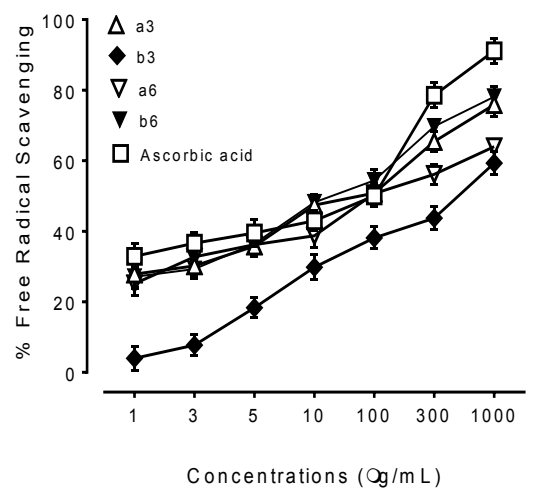

Figure 6.

Concentration-response curve for 1,1-diphenyl-2picrylhydrazyl (DPPH) free radical scavenging activity of $N$-\{4-[(5-sulfanyl-1,3,4-oxa diazol-2yl)methoxy]phenyl]acetamide (a3), 5-[(naphthalen-2yloxy)methyl]-1,3,4-oxadiazole-2thiol (b3) 3phenyl5-(o-hydroxyphenyl)-1-[2-(p-N-acetylamino phenoxy)acetyl]pyrazole (a6), 3-phenyl-5-(o-hydroxyphenyl)-

1-[2-(2'-naphthyloxy)acetyl] pyrazole (b6) and ascorbic acid. Values shown are mean \pm SEM, $n=4$

Effect on DPPH free radical scavenging

The results of concentration-dependant free radical scavenging activity of a3, b3, a6 and ascorbic acid are shown in Figure 6. The a3, b3, a6, b6 and ascorbic showed radical scavenging effect at $\mathrm{EC}_{50}$ values of $170.3,336.8,100.0,141.5$ and $100.0 \mu \mathrm{g} / \mathrm{mL}$ respectively.

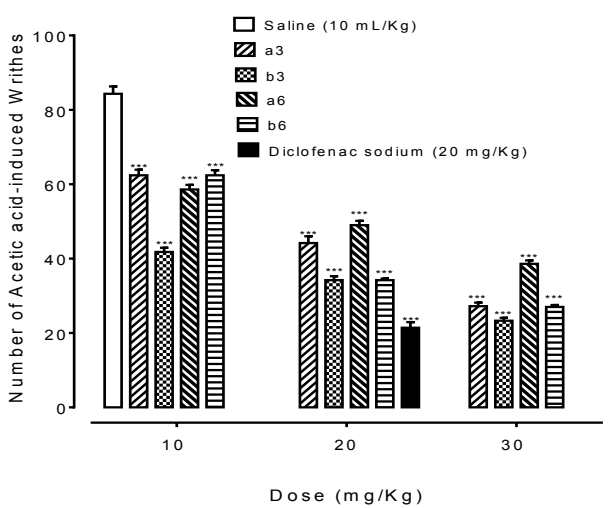

Figure 7.

Bar chart showing inhibition of acetic acid-induced writhings by of $N$-\{4-[(5-sulfanyl 1,3,4-oxadiazol-2yl) methoxy] phenyl]acetamide (a3), 5-[(naphthalen2-yloxy) methyl]1,3,4-oxadiazole-2-thiol (b3), 3phenyl-5-(o-hydroxyphenyl)-1-[2-(p-Nacetylaminophenoxy) acetyl]pyrazole (a6) and 3-phenyl-5-(ohydroxyphenyl)-1-[2-(2'naphthyloxy)acetyl]pyrazole (b6) and diclofenac sodium $(20 \mathrm{mg} / \mathrm{Kg})$ in mice. Data expressed as mean \pm SEM, $n=5$. $^{* * *} \mathrm{p}<0.001$ vs saline group, one way ANOVA with post-hoc Tukey test

\section{Effect on acetic acid-induced writhing}

The results of dose-dependent reduction caused by a3, b3, a6, b6 and diclofenac sodium in numbers of acetic acid-induced writhes in mice are shown in 
FARMACIA, 2018, Vol. 66, 5

Figure 7. At $10 \mathrm{~mL} / \mathrm{kg}$, numbers of writhes recorded for saline group was $83.4 \pm 0.347$. At a dose of 10 , 20 and $30 \mathrm{mg} / \mathrm{kg}$, a3 significantly decreased the numbers of writhes to $62.4 \pm 0.509,34.2 \pm 0.509$ and $27.2 \pm 0.376$ ( $\mathrm{p}<0.001$ vs saline group) respectively. b3 decreased the numbers of writhes to $41.8 \pm 1.114$, $34.2 \pm 1.068$ and $23.3 \pm 0.800(\mathrm{p}<0.001$ vs saline group) respectively. a6 decreased the numbers of writhes to $58.6 \pm 1.208,49.0 \pm 1.140$ and $38.6 \pm 0.927$ ( $\mathrm{p}<0.001$ vs saline group) respectively. b6 decreased the numbers of writhes to $62.4 \pm 1.35,34.2 \pm 0.44$ and $27.0 \pm 0.50(\mathrm{p}<0.001 v s$ saline group $)$ respectively. Diclofenac sodium decreased the numbers of writhes to $21.4 \pm 0.509$ ( $\mathrm{p}<0.001$ vs saline group). Effect on carrageenan-induced paw oedema The results of dose-dependent $(10-20 \mathrm{mg} / \mathrm{kg})$ paw volume displacement caused by a3, b3, a6, b6 and diclofenac sodium following carrageenan-induced paw oedema in mice are presented in Table VII.

Table VII

Composition and codification of metronidazole gel formulations

\begin{tabular}{|c|c|c|c|c|c|}
\hline Test sample & $\mathbf{0 ~ h r}$ & $\mathbf{1 ~ h r}$ & $\mathbf{2 ~ h r}$ & $\mathbf{3 ~ h r}$ & $\mathbf{4} \mathbf{~ h r}$ \\
\hline Saline $(10 \mathrm{~mL} / \mathrm{kg})$ & $0.35 \pm 0.005$ & $0.41 \pm 0.005$ & $0.45 \pm 0.005$ & $0.52 \pm 0.003$ & $0.51 \pm 0.005$ \\
\hline $\mathrm{a} 3(10 \mathrm{mg} / \mathrm{kg})$ & $0.36 \pm 0.003$ & $0.34 \pm 0.005$ & $0.32 \pm 0.005$ & $0.30 \pm 0.005^{*}$ & $0.28 \pm 0.002$ \\
\hline $\mathrm{a} 3(20 \mathrm{mg} / \mathrm{kg})$ & $0.36 \pm 0.003$ & $0.33 \pm 0.003$ & $0.25 \pm 0.002$ & $0.22 \pm 0.002^{* *}$ & $0.20 \pm 0.003$ \\
\hline $\mathrm{b} 3(10 \mathrm{~mL} / \mathrm{kg})$ & $0.37 \pm 0.007$ & $0.31 \pm 0.006$ & $0.27 \pm 0.004$ & $0.23 \pm 0.006^{* *}$ & $0.22 \pm 0.004^{* *}$ \\
\hline $\mathrm{b} 3(20 \mathrm{mg} / \mathrm{kg})$ & $0.35 \pm 0.005$ & $0.27 \pm 0.004$ & $0.22 \pm 0.006^{* *}$ & $0.20 \pm 0.005^{* *}$ & $0.19 \pm 0.003$ \\
\hline $\mathrm{a} 6(10 \mathrm{~mL} / \mathrm{kg})$ & $0.36 \pm 0.005$ & $0.32 \pm 0.004$ & $0.30 \pm 0.003$ & $0.28 \pm 0.003^{*}$ & $0.26 \pm 0.003^{*}$ \\
\hline $\mathrm{a} 6(20 \mathrm{mg} / \mathrm{kg})$ & $0.36 \pm 0.004$ & $0.33 \pm 0.002$ & $0.28 \pm 0.002$ & $0.26 \pm 0.003^{*}$ & $0.25 \pm 0.003$ \\
\hline $\mathrm{b} 6(10 \mathrm{~mL} / \mathrm{Kg})$ & $0.37 \pm 0.004$ & $0.34 \pm 0.002$ & $0.31 \pm 0.003$ & $0.28 \pm 0.003^{*}$ & $0.28 \pm 0.003$ \\
\hline $\mathrm{b} 6(20 \mathrm{mg} / \mathrm{Kg})$ & $0.35 \pm 0.005$ & $0.29 \pm 0.003$ & $0.28 \pm 0.004$ & $0.25 \pm 0.004^{*}$ & $0.20 \pm 0.005$ \\
\hline Diclofenac sodium $(20 \mathrm{mg} / \mathrm{kg})$ & $0.35 \pm 0.005$ & $0.32 \pm 0.005$ & $0.27 \pm 0.005$ & $0.22 \pm 0.003^{* *}$ & $0.16 \pm 0.004^{* *}$ \\
\hline
\end{tabular}

Values are shown as mean \pm SEM, $\mathrm{n}=5 .{ }^{*} \mathrm{p}<0.05,{ }^{* *} \mathrm{p}<0.01 \mathrm{vs}$ saline group one way ANOVA with post-hoc Tukey test

\section{Acute toxicity analysis}

The compounds a3, b3, a6 and b6 did not caused mortality up to the dose of $750 \mathrm{mg} / \mathrm{kg}$.

Docking is one of the tools utilized in order to perform the affinity of the novel oxadiazoles and pyrazoles derivatives to their respective targets. The main purpose of docking is the preliminary information about affinity of any compound before switching to in-vivo experimentation. The docking of the selected 1,3,4-oxadiazole and pyrazole novel derivatives was carried out through patch dock, giving binding in the form of conventional hydrogen bonds, covalent bonds and carbon hydrogen bonds along with other weak forces (wander wall's forces, and pi hydrogen bonds) with its binding energy value or E-value ranges from -107 to $-297 \mathrm{Kcal} / \mathrm{mol}$. The number of bond formed by a ligand range from 1 to 5 [20]. The test compounds including a3, b3, a6 and b6 showed affinity with EGFR, tubulin, COX-2 and 5-LOX. As it is a comparative study so the results of the docking of ligands were compared with erlotinib, vincristine, diclofenac sodium and zileuton. In case of docking for anticancer potential, a3, b3, a6 and b6 exhibits moderate affinities with EGFR, but as all of the ligands formed single hydrogen bond, the differentiation between ligands for good affinities is carried out by considering unfavourable bumps. These bumps are seen in all the ligands except a3. On the basis of absence of these bumps, a3 showed highest binding stability and good affinity to EGFR. More over the binding of $\mathrm{b} 3, \mathrm{a} 6$, and $\mathrm{b} 6$ also shows that these compounds bind near to the binding site of erlotinib. In addition, a3, b3, a6 and b6 were also docked against tubulin. a3 and b6 showed good affinities, while b3 and a6 were recorded with less affinities. Among a3 and b6, it is concluded that b6 possess good affinity based on the reason that it develops attractive charges with tubulin. The results of all the ligands were compared with vincristine, which showed best interactions not only in the form of hydrogen bonds but also interacts with its targets through 2 covalent bonds which is the reason for it best anticancer potential. $\mathrm{a} 3$ and $\mathrm{b} 6$ were recorded with less affinities while $\mathrm{b} 3$ and $\mathrm{a} 6$ showed good affinities with COX-2. It is concluded that b3 possess good affinity because of minimum numbers of unfavourable bumps in comparison with a6. Moreover the binding stability of b3 is also highest as compare to a6. Three hydrogen bonds with single unfavourable bump is the reason on good affinity as well as analgesic potential for relieving pain. In case of docking for antiinflammatory activity, a3, b3, a6 and b6 showed binding to 5-LOX and it is concluded that b3 again possess the highest affinity with 5-LOX similar to zileuton. Zileuton also showed two covalent bonds which is the reason for its best anti-inflammatory potential. Docking was carried out in order to confirm the affinities of test compounds including a3, b3, a6 and b6 with targets involve for anticancer, analgesic and anti-inflammatory activities. Further confirmation of these test compounds for the mentioned activities was carried out through in vitro and in-vivo pharmacological experimentations.

In the in vitro investigations, the test compounds were screened for toxicity assessment, tumour inhibition and radical scavenging. The lethality of the brine 
FARMACIA, 2018, Vol. 66, 5

shrimps is registered because of the less developed membrane susceptible to cytotoxic chemicals or may be caused by DNA disruption [21]. b6 presented the most potent cytotoxic effect. The order of cytotoxicity was b6 $>\mathrm{a} 3>\mathrm{a} 6>\mathrm{b} 3$. Methotrexate was utilized as positive control. The exact mechanism of methotrexate is unknown, but it may be possible that produces its larvicidal effect by denaturing DNA of brine shrimp and causes lethality of brine shrimp [22]. This cytotoxicity was further confirmed by screening a3, b3, a6 and $\mathrm{b} 6$ for antitumor activity. But before this assay the compounds were also checked for antibacterial activity against Agrobacterium tumefacians. This antibacterial assay reveals that the compounds had no antibacterial activity against Agrobacterium tumefacians and thus tumour inhibition was not because of antibacterial nature [23]. The study explains, that those compounds which have potential to inhibit tumour following potato disc tumour assay is due to the inhibition of DNA transfer of Agrobacterium tumefacians [24]. Moreover the anticancer potential of 1,3,4-oxadiazoles and pyrazoles derivatives needs further investigations by screening all the compounds through cell line assays utilizing human cancer cells. The in vitro investigations reveals that b6 possess the highest potential for tumour inhibition. The order of test compounds for tumour inhibition was b6 $>\mathrm{a} 3>$ $\mathrm{a} 6>\mathrm{b} 3$. Thus it is concluded that docking which also explain the highest affinity of b6, can be correlated to its highest in vitro pharmacological activity. Antioxidant activity of all the tested compounds and ascorbic acid can be explained by the aromatic nature and electron donating group on benzene ring [25]. Increasing the number of electron donating group will result in increasing the free radical scavenging activity. a6 because of its electron donating groups exhibited highest antioxidant activity followed by test agent b6 which also possesses $\mathrm{OH}$ as electron donating group. $\mathrm{a} 3$ and $\mathrm{b} 3$ have moderate antioxidant activity. In other words, pyrazole derivatives were found to be more active in comparison with oxadiazole derivatives as far as antioxidant activity is concerned. Writhing is basically an abdominal constrictions caused by the release of different types of mediators after the i.p. injection of freshly prepared acetic acid. This noxious response can be prevented by drugs which have the ability to stop the synthesis of these chemicals. NSAIDs got this ability by stopping their production through blocking of COX-2. The reduction in number of writhes in treated group explains the same phenomenon of blocking the production of mediators by inhibiting COX-2 by the test compounds. Thus, it is concluded that docking which also explain the highest affinity of $\mathrm{b} 3$ to COX-2 can be correlated to its highest in-vivo analgesic activity. The antiinflammatory potential of the test compounds was determined by using carrageenan induced paw oedema. The method explains the reduction in paw oedema after 2,3 and 4 ( $2^{\text {nd }}$ phase) hours. This reduction is because of the blockage of prostaglandin synthesis by inhibition of COX-2 [26]. The reduction of paw volume by $\mathrm{a} 3$ and $\mathrm{b} 3$ up to 3 hours is because of the short half-life of 1,3,4- oxadiazoles while the longer half-life of pyrazole a6 and b6 is responsible for reduction of paw oedema after 3 to 4 hours. Moreover, the suggested mechanism for preventing oedema is supported by docking studies through the inhibition of COX-2.

The safety of all the compounds was assessed by screening all of them for acute toxicity. It was observed that, even at high doses, all the compounds were safe producing no mortality after 24 hours of administration. The administration of high doses without serious morbidity and mortality gives an idea that these compounds are safe even at these doses and have a large therapeutic index. Further investigation is needed in order to confirm its stability, safety and toxicity profile, suitability for oral administration, pharmacokinetic and pharmacodynamics confirmation before launching these new moieties in market.

\section{Conclusions}

In-silico studies showed affinities of novel 1,3,4 oxadiazole and pyrazole derivatives: $N$ - $\{4-[(5$-sulfanyl1,3,4-oxadiazol-2yl)methoxy]phenyl acetamide, 5[(naphthalen-2-yloxy)methyl]-1,3,4-oxadiaszole2thiol, 3-phenyl5-(o-hydroxyphenyl)-1-[2-(p-N acetylaminophenoxy) acetyl pyrazole and 3phenyl-5-(ohydroxyphenyl)-1-[2(2'naphthyloxy)acetyl] pyrazole against targets: EGFR, tubulin, COX-2 and 5-LOX. In vitro and in-vivo pharmacological investigations revealed that aforementioned derivatives exhibit cytotoxicity, tumour inhibition, radical scavenging, analgesic and anti-inflammatory activities.

\section{References}

1. Bhandari SV, Bothara KG, Raut MK, Patil AA, Sarkate AP, Mokale VJ, Design, synthesis and evaluation of antiinflammatory, analgesic and ulcerogenicity studies of novel S-substituted phenacyl-1, 3, 4oxadiazole-2 thiol and Schiff bases of diclofenac acid as non ulcerogenic derivatives. Bioorganic \& Medicinal Chemistry, 2008; 16: 1822-1831.

2. Palaska E, Şahin G, Kelicen P, Durlu NT, Altinok $\mathrm{G}$, Synthesis and anti-inflammatory activity of 1acylthiosemicarbazides, 1,3,4-oxadiazoles, 1,3,4thiadiazoles and 1,2,4-triazole-3-thiones. IL Farmaco, 2002; 57: 101-107.

3. Şahin G, Palaska E, Ekizoglu M, Ozalp M, Synthesis and antimicrobial activity of some 1,3, 4-oxadiazole derivatives. IL Farmaco, 2002; 57: 539-542.

4. Singh R, Chouhan A, Various approaches for synthesis of 1,3,4-oxadiazole derivatives and their pharmacological activity. World J Pharmacol Pharmaceut Sci., 2014; 3: 1474-1505. 
5. Al-Saadi MS, Synthesis and In-vitro antitumor activity of some fused pyrazole and pyrazoline ring systems. Saudi Pharmaceut J., 2008; 16: 135-145.

6. Martins DM, Torres BG, Spohr PR, Machado P, Bonacorso HG, Zanatta N, Martins MA, Emanuelli T, Antioxidant potential of new pyrazoline derivatives to prevent oxidative damage. Basic \& Clinical Pharmacology \& Toxicology, 2009; 104: 107-112.

7. Maggio B, Daidone G, Raffa D, Plescia S, Mantione L, Cutuli VMC, Mangano NG, Caruso A, Synthesis and pharmacological study of ethyl 1methyl-5(substituted 3, 4-dihydro-4-oxoquinazolin-3-yl)-1Hpyrazole-4 acetates. Eur J Med Chem., 2001; 36: 737-742.

8. Daidone G, Maggio B, Raffa D, Plescia S, Bajardi ML, Caruso A, Cutuli VMC, Amico-Roxas M, Synthesis and pharmacological study of ethyl 1methyl-5-[2-substituted-4-oxo-3(4H)-quinazolinyl]1H-pyrazole-4-acetates. Eur J Med Chem., 1994; 29 : 707-711.

9. Muhammad SA, Nadeem H, Sadiq A, Computational drug designing against salmonella typhi, a causative agent of typhoid. Intl J Pharmceutics, 2014; 4(1): 252-255.

10. Toma A, Leonte D, Zaharia V, Heterocycles 40 . The lipophilicity evaluation of some new pyridin-3/4-ylthiazolo[3,2-b][1,2,4]triazole compounds with antiinflammatory activity by RP-TLC and computational methods. Farmacia, 2017; 65(1): 23-28.

11. Hamada NMM, Sharshira EM, Synthesis and antimicrobial evaluation of some heterocyclic chalcone derivatives. Molecules, 2011; 16: 2304-2312.

12. National Research Council, 1996. Guide for the care and use of laboratory animals. Institute of Laboratory Animal Resources, Commission on Life Sciences. National Academy of Sciences, Washington, DC, USA.

13. Parvathy NG, Prathap M, Mukesh M, Thomas L, Design, synthesis and molecular docking studies of benzothiazole derivatives as anti microbial agents. Int J Pharm Pharmaceut Sci., 2013; 5(2): 101-106.

14. Bibi G, Ullah N, Mannan A, Mirza B, Antitumor, cytotoxic and antioxidant potential of Aster thomsonii extracts. Af J Pharm Pharmacol., 2011; 5: 252-258.

15. Coker P.S., Radecke J., Guy C., Camper N.D., Potato disc tumor induction assay: a multiple mode of drug action assay. Phytomedicine, 2003; 10: 133-138.
16. Molyneux $\mathrm{P}$, The use of the stable free radical diphenylpicrylhydrazyl (DPPH) for estimating antioxidant activity. Songklanakarin J Sci Tech., 2004; 26: 211-219.

17. Ahmed F, Selim MST, Das AK, Choudhuri MSK, Antiinflammatory and antinociceptive activities of Lippia nodiflora Linn. Die Pharmazie - An Int J Pharmaceutic Sci., 2004; 59: 329-330.

18. Farghaly AA, Bekhit AA, Young Park J, Design and synthesis of some oxadiazolyl, thiadiazolyl, thiazolidinyl, and thiazolyl derivatives of $1 \mathrm{H}$ pyrazole as anti inflammatory antimicrobial agents. Archiv der Pharmazie, 2000; 333: 53-57.

19. Akhila JS, Shyamjith D, Alwar MC, Acute toxicity studies and determination of median lethal dose. Current Science, 2007; 93(7): 917-920.

20. Ghanei S, Lari J, Eshghi H, Saadatmandzadeh M, Synthesis and docking analysis of new heterocyclic system N1,N4-bis (2-chloroquinolin-3-yl)methylene) benzene-1,4-diamine as potential human AKT1 Inhibitor. Iran $J$ Pharmaceutic Res., 2016; 15(3): 321-327.

21. Meyer BN, Ferrigni NR, Putnam JE, Jacobsen LB, Nichols DJ, McLaughlin JL, Brine shrimp: a convenient general bioassay for active plant constituents. Planta Medica, 1982; 45: 31-34.

22. Zeng H, Song WQ, Chen RY, Study of a DNA sequence from brine shrimp artemia containing a novel DM domain. Shi Yan Sheng Wu Xue Bao, 2004; 37: 423-423.

23. Abadi AH, Eissa AAH, Hassan GS, Synthesis of novel 1,3,4 trisubstituted pyrazole derivatives and their evaluation as antitumor and antiangiogenic agents. Chem Pharmaceutic Bull., 2003; 51: 838-844.

24. Gelvin SB, Agrobacterium-mediated plant transformation. The biology behind the gene-jockeying tool. Microbiol Mol Biol Rev., 2003; 67: 16-37.

25. Padmaja A, Rajasekhar C, Muralikrishna A, Padmavathi $\mathrm{V}$, Synthesis and antioxidant activity of oxazolyl/thiazolyl sulfonylmethyl pyrazoles and isoxazoles. Eur J Med Chem., 2011; 46: 5034-5038.

26. Vinegar R, Schreiber W, Hugo R, Biphasic development of carrageenan edema in rats. J Pharm Exp Therap., 1969; 166: 96-103. 